\title{
Overall Survival After Whole-Brain Radiation Therapy for Intracerebral Metastases from Testicular Cancer
}

\author{
DIRK RADES ${ }^{1}$, LIESA DZIGGEL $^{1}$, THEO VENINGA ${ }^{2}$, AMIRA BAJROVIC ${ }^{3}$ and STEVEN E. SCHILD ${ }^{4}$ \\ ${ }^{1}$ Department of Radiation Oncology, University of Lubeck, Lubeck, Germany; \\ ${ }^{2}$ Department of Radiotherapy, Dr. Bernard Verbeeten Institute, Tilburg, the Netherlands; \\ ${ }^{3}$ Department of Radiotherapy, University Medical Center Eppendorf, Hamburg, Germany; \\ ${ }^{4}$ Department of Radiation Oncology, Mayo Clinic, Scottsdale, AZ, U.S.A.
}

\begin{abstract}
Background/Aim: To identify predictors and develop a score for overall survival of patients with intracerebral metastasis from testicular cancer. Patients and Methods: Whole-brain radiation therapy program, age, Karnofsky performance score (KPS), number of intracerebral metastases, number of other metastatic sites and time between testicular cancer diagnosis and radiation therapy were analyzed for their association with overall survival in eight patients. Results: KPS of 80-90\% was significantly associated with better overall survival $(p=0.006)$, one or no other metastatic sites showed a trend for a better outcome $(p=0.10)$. The following scores were assigned: KPS $60-70 \%=0$ points, KPS $80-90 \%=1$ point, $\geq 2$ other metastatic sites $=0$ points, $0-1$ other metastatic sites $=1$ point. Two groups, with 0 and with 1-2 points, were formed. Overall survival rates were $33 \% \mathrm{vs.}$ $100 \%$ at 6 months and $0 \%$ vs. $100 \%$ at 12 months ( $p=0.006)$, respectively. Conclusion: A simple instrument enabling physicians to judge the overall survival of patients with intracerebral metastasis from testicular cancer is provided.
\end{abstract}

Radiation therapy is by far the most frequently used type of treatment for intracerebral metastases, mainly in the form of whole-brain radiation therapy (1). However, for radiation oncologists, intracerebral metastasis from testicular cancer is a very rare situation. These patients account for only about $0.5 \%$ of patients with cancer with intracerebral spread. Therefore, only very little is known about the results of and prognosis after radiation therapy in this patient group. When presenting to a

Correspondence to: Professor Dirk Rades, MD, Department of Radiation Oncology, University of Lübeck, Ratzeburger Allee 160, 23538 Lübeck, Germany. Tel: +49 4515006661, Fax: +49 4515003324, e-mail: rades.dirk@gmx.net

Key Words: Testicular cancer, intracerebral metastases, whole-brain radiation therapy, overall survival, prediction. radiation oncologist for irradiation of other systemic metastases, patients with testicular cancer experience a much more favorable outcome than the majority of patients with other metastatic cancer (2). This may also apply to patients with testicular cancer who have developed intracerebral lesions. Assuming this is true, these patients may require treatment strategies different from those for other patients with intracerebral metastases (3-5). Therefore, the current study was carried out to determine the overall survival rate of patients treated with whole-brain radiation therapy for intracerebral metastasis from testicular cancer. An additional goal was to identify predictors of overall survival that can be used for a prognostic instrument enabling physicians to judge the overall survival times of such patients. This is important when physicians wish to optimally tailor their treatment regimen to the situation of a particular patient with intracerebral metastasis from testicular cancer.

\section{Patients and Methods}

Eight patients who received whole-brain radiation therapy for intracerebral metastases were included in this study. The wholebrain radiation therapy was administered with one of the two most common schedules, namely 20 Gy in five fractions and 30 Gy in 10 fractions, or with a higher dose, i.e. $40 \mathrm{~Gy}$ in 20 fractions. The program of whole-brain radiation therapy as well as age $(\leq 34 v s$. $\geq 35$ years; median age was 34.5 years), Karnofsky performance score (KPS) (80-90\% vs. 60-70\%), the number of intracerebral metastases (limited: 1-3 vs. multiple: $\geq 4$ ), number of other (i.e. extracerebral) metastatic sites $(0-1 v s . \geq 2)$ and the time between diagnosis of testicular cancer and whole-brain radiation therapy $(\leq 8$ $v s . \geq 9$ months; median time was 8.5 months) were evaluated for associations with overall survival. For the analyses regarding overall survival, the Kaplan-Meier method and the Wilcoxon test were applied. Significance was defined as $p<0.05$, a trend as $p \leq 0.10$.

\section{Results}

In the entire series, the 6-month and 12-month overall survival rates were $75 \%$ and $63 \%$, respectively. On overall survival 
Table I. Results of the analysis of overall survival.

\begin{tabular}{|c|c|c|c|}
\hline Variable & At 6 months & At 12 months & $p$-Value \\
\hline \multicolumn{4}{|l|}{ Whole-brain radiation therapy } \\
\hline $20 \mathrm{~Gy} / 5$ fractions or $30 \mathrm{~Gy} / 10$ fractions $(\mathrm{n}=3)$ & 67 & 67 & \\
\hline $40 \mathrm{~Gy} / 20$ fractions $(\mathrm{n}=5)$ & 80 & 60 & 0.88 \\
\hline \multicolumn{4}{|l|}{ Age } \\
\hline$\leq 34$ years $(n=4)$ & 75 & 75 & \\
\hline$\geq 35$ years $(n=4)$ & 75 & 50 & 0.56 \\
\hline \multicolumn{4}{|l|}{ Karnofsky performance score } \\
\hline $80-90 \%(\mathrm{n}=5)$ & 100 & 100 & \\
\hline $60-70 \%(n=3)$ & 33 & 0 & 0.006 \\
\hline \multicolumn{4}{|l|}{ Number of intracerebral metastases } \\
\hline Limited ( $1-3$ lesions $)(n=4)$ & 100 & 100 & \\
\hline Multiple ( $\geq 4$ lesions) $(n=4)$ & 50 & 25 & 0.13 \\
\hline \multicolumn{4}{|l|}{ Number of other metastatic sites } \\
\hline $0-1(\mathrm{n}=3)$ & 100 & 100 & \\
\hline$\geq 2(\mathrm{n}=5)$ & 60 & 40 & 0.10 \\
\hline \multicolumn{4}{|c|}{ Time between diagnosis of testicular cancer and whole-brain radiation therapy } \\
\hline$\leq 8$ months $(\mathrm{n}=4)$ & 75 & 25 & \\
\hline$\geq 9$ months $(\mathrm{n}=4)$ & 75 & 75 & 0.56 \\
\hline
\end{tabular}

Significant $p$-values are shown in bold.

analysis (Table I), a KPS of $80-90 \%$ was significantly associated with a better outcome $(p=0.006)$. In addition, presence of only one or no other metastatic sites showed a trend for a better outcome $(p=0.10)$. These two parameters were subsequently used for the development of an instrument for rating the overall survival of patients with intracerebral metastases from testicular cancer. The following scores were assigned: KPS of $60-70 \%=0$ points, KPS of $80-90 \%=1$ point, $\geq 2$ other metastatic sites $=0$ points; and $0-1$ other metastatic sites $=1$ point. Thus, total scores were either 0,1 or 2 points. The overall survival rates at 6 months were $33 \%, 100 \%$ and $100 \%$, respectively, and the overall survival rates at 12 months $0 \%, 100 \%$ and $100 \%$, respectively. Considering these rates, two groups were formed, with 0 points and with 1-2 points, resulting in overall survival rates at 6 and 12 months of 33\% vs. $100 \%$ and $0 \%$ vs. $100 \%$, respectively $(p=0.006)$. Figure 1 shows the Kaplan-Meier survival curves of these two groups.

\section{Discussion}

In comparison to other cancer types, patients with testicular cancer have a much better prognosis (2). In order to deliver the best available therapy to an individual patient, considerable research has been carried out for patients with testicular cancer, including studies that aimed to define preclinical and clinical factors serving as markers for treatment outcomes (6-10). If patients with testicular cancer develop intracerebral metastases, whole-brain radiation therapy may be indicated (1). For this specific situation, to our knowledge no study has been reported that was

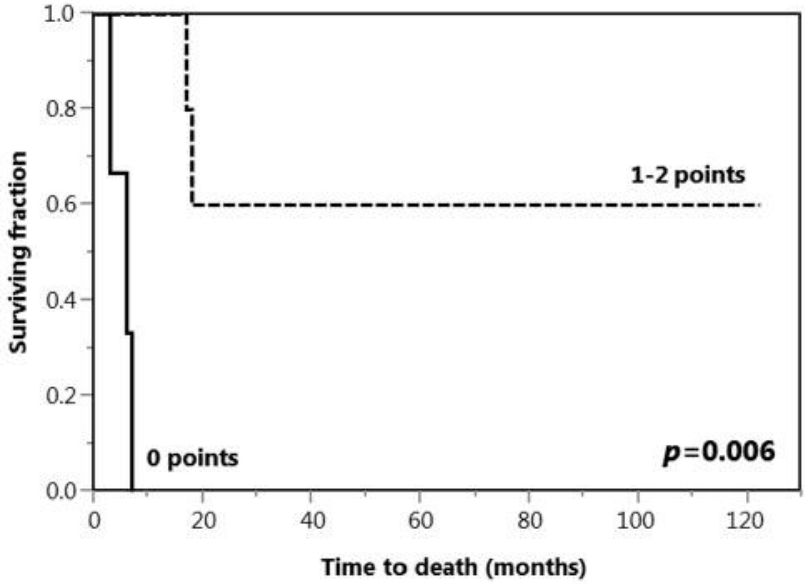

Figure 1. Overall survival curves of the two groups scoring 0 points and 1-2 points.

performed to define prognostic markers for overall survival in such cases. The present study aimed to fill this gap. Knowing a patient's overall survival time as precisely as possible would be momentous if one wishes to administer the optimal radiation treatment to a particular patient.

It has been well recognized that for patients with a poor overall survival prognosis, a 1-week course of whole-brain radiation therapy with $20 \mathrm{~Gy}$ in five fractions is the best option (1). A previous study of more than 400 patients with intracerebral metastases from many different cancer types 
showed that 20 Gy in five fractions resulted in similar 6month overall survival rate as the worldwide most frequently used 2-week whole-brain radiation therapy program of $30 \mathrm{~Gy}$ in 10 fractions (24\% vs. 27\%, $p=0.29)$ (11). In another study including patients with intracerebral metastases from various cancer types with mean overall survival time of at least 12 months, whole-brain radiation therapy with 40 Gy in 20 fractions (4 weeks) was significantly superior to $30 \mathrm{~Gy}$ in 10 fractions regarding the overall survival rate at 12 months $(61 \%$ vs. 50\%, $p=0.008$ ) (3). Thus, in general, patients with a poor expected overall survival should receive $20 \mathrm{~Gy}$ in five fractions, those with an intermediate prognosis $30 \mathrm{~Gy}$ in 10 fractions, and those with a good prognosis $40 \mathrm{~Gy}$ in 20 fractions. In selected patients with a very limited number of intracerebral metastases and an intermediate or a good overall survival prognosis, whole-brain radiation therapy may be supplemented or replaced by local radiation therapy in form of stereotactic radiosurgery (a single fraction with a high dose, for example of 20-24 Gy) or fractionated stereotactic radiation therapy (for example three fractions of 10-12 Gy) $(4,5)$.

These considerations highlight how important it is to know a patient's remaining overall survival time when the best treatment option is to be decided. This also applies to patients with testicular cancer who are planned to be irradiated for intracerebral metastases. In this study, one significant marker for overall survival was identified, the performace status given as KPS. In addition, a trend was found for the number of other metastatic sites outside of the brain. Based on these two clinical markers, a simple scoring instrument was designed, which included two groups (with 0 points and 1-2 points) with a great difference regarding the overall survival rates at both 6 and 12 months. In the 0 -points group, the 6month overall survival rate was only $33 \%$, and no patient survived longer than 7 months. Therefore, these patients appear to be good candidates for $20 \mathrm{~Gy}$ in five fractions (11). In the group of patients with 1-2 points, all patients survived for 12 months or longer and, therefore, should receive $40 \mathrm{~Gy}$ in 20 fractions to achieve best possible outcomes (3). In the latter group, local radiation therapy may be considered for selected patients with 1-3 intracerebral lesions in addition to or instead of whole-brain radiation therapy $(1,4,5)$. Whether stereotactic radiosurgery or fractionated stereotactic radiation therapy can be given without whole-brain radiation therapy depends on the risk of developing new intracerebral metastases outside of the treated lesions. This risk can be estimated with another scoring instrument specifically designed to answer this question (12).

In summary, a simple instrument is provided that enables physicians to judge the overall survival times of patients with intracerebral metastases from testicular cancer. With this new instrument, the decision regarding the treatment protocol for a particular patient belonging to this rare group can be made easier.

\section{Conflicts of Interest}

On behalf of all Authors, the corresponding Author states that there is no conflict of interest related to this study.

\section{References}

1 Tsao MN, Rades D, Wirth A, Lo SS, Danielson BL, Gaspar LE, Sperduto PW, Vogelbaum MA, Radawski JD, Wang JZ, Gillin MT, Mohideen N, Hahn CA and Chang EL: Radiotherapeutic and surgical management for newly diagnosed brain metastasis(es): An American Society for Radiation Oncology evidence-based guideline. Pract Radiat Oncol 2: 210-225, 2012.

2 Haugnes HS, Solhaug O, Stenberg J, Hjelle LV and Bremnes RM: Seminoma patients treated at a minor oncological department during 1986-2010: treatment and outcome. Anticancer Res 34: 4253-4560, 2014.

3 Rades D, Panzner A, Dziggel L, Haatanen T, Lohynska R and Schild SE: Dose-escalation of whole-brain radiotherapy for brain metastasis in patients with a favorable survival prognosis, Cancer 118: 3853-3859, 2012.

4 Andrews DW, Scott CB, Sperduto PW, Flanders AE, Gaspar LE, Schell MC, Werner-Wasik M, Demas W, Ryu J, Bahary JP, Souhami L, Rotman M, Mehta MP and Curran WJ Jr.: Whole-brain radiation therapy with or without stereotactic radiosurgery boost for patients with one to three brain metastases: phase III results of the RTOG 9508 randomised trial. Lancet 363: 1665-1672, 2004.

5 Rades D, Pluemer A, Veninga T, Hanssens P, Dunst J and Schild SE: Whole-brain radiotherapy versus stereotactic radiosurgery for patients in recursive partitioning analysis classes 1 and 2 with 1 to 3 brain metastases. Cancer 110: 2285-2292, 2007.

6 Hjelle LV, Gundersen PO, Oldenburg J, Brydøy M, Tandstad T, Wilsgaard T, Fosså SD, Bremnes RM and Haugnes HS: Longterm platinum retention after platinum-based chemotherapy in testicular cancer survivors: a 20-year follow-up study. Anticancer Res 35: 1619-1625, 2015.

7 Burczynska BB, Kobrouly L, Butler SA, Naase M and Iles RK: Novel insights into the expression of CGB1 and 2 genes by epithelial cancer cell lines secreting ectopic free hCG $\beta$. Anticancer Res 34: 2239-2248, 2014.

8 Heidegger I, Borena $\mathrm{W}$ and Pichler R: The role of human papilloma virus in urological malignancies. Anticancer Res 35: 2513-2519, 2015.

9 Bezan A, Gerger A and Pichler M: MicroRNAs in testicular cancer: implications for pathogenesis, diagnosis, prognosis and therapy. Anticancer Res 34: 2709-2713, 2014.

10 Spiekermann M, Dieckmann KP, Balks T, Bullerdiek J and Belge G: Is relative quantification dispensable for the measurement of microRNAs as serum biomarkers in germ cell tumors? Anticancer Res 35: 117-121, 2015.

11 Rades D, Kieckebusch S, Lohynska R, Veninga T, Stalpers LJ, Dunst $\mathrm{J}$ and Schild SE: Reduction of overall treatment time in patients irradiated for more than three brain metastases. Int $\mathbf{J}$ Radiat Oncol Biol Phys 69: 1509-1513, 2007.

12 Huttenlocher S, Dziggel L, Hornung D, Blanck O, Schild SE and, Rades D: A new prognostic instrument to predict the probability of developing new cerebral metastases after radiosurgery alone, Radiat Oncol 9: 215, 2014

Received July 7, 2016

Revised July 21, 2016

Accepted July 22, 2016 